\title{
Study on Seaman Comprehensive Quality in Emergency Evaluation Index System
}

\author{
Xuling $\mathrm{Hu}^{1, \mathrm{a}}$, Xiuping Sui ${ }^{1}$, Mingqin,Shao ${ }^{1}$, \\ Zhuanzhao Liu ${ }^{1}$ and Shucui Jiang ${ }^{1}$ \\ ${ }^{1}$ Shandong Jiaotong University Maritime College, Shandong, China \\ awh-hxl@163.com
}

Keywords: Crew Quality, Emergency, Evaluation Index System

Abstract. With the increasing of piracy attacking actions in international waters and risk factors of navigation, safe and fast operation of the ship, even the safety of life and property at sea, it is particularly important to focus on vessel safety, human life, emergency status of the crew's comprehensive quality. A state of emergency crew quality evaluation index system is established in this paper, divided into a level indicators and secondary indicators, through a questionnaire survey of experts to get the weight of each index. We use analytic hierarchy process to establish mathematical model, combining qualitative and quantitative, and draw a conclusion: In case of emergency, the crew psychological quality, practical skills, physical fitness, theoretical knowledge and English level are the most important factors to overcome the difficulties and dangers.

\section{Introduction}

According to a recent report issued by the international maritime bureau, piracy attacking has been spreading worldwide. At the same time, due to the impact of extreme weather, typhoons, earthquakes, tsunamis has brought great adverse impact on navigation safety. In the face of emergency, what kind of quality should the crew have? Which quality is the most important? This paper establishes the evaluation index system of the quality of the crew in the emergency condition.

We establish mathematical model, by using analytic hierarchy process, combining qualitative and quantitative, to draw a conclusion that in case of emergency, the crew psychological quality, physical quality, practical skills, theoretical knowledge and English level are the most important factors to overcome the difficulties and dangers.

\section{Construction of evaluation index system}

The evaluation index system of the quality of the crew is based on the comprehensive quality of the crew in the emergency situation. The main purpose is to provide some suggestions for the modern crew based on the above principles. This paper establishes the evaluation index system of the quality of the crew in emergency condition as shown in Fig. 1. For the crew, the comprehensive quality includes psychological quality, physical quality, practical skills, theoretical knowledge and communicative ability. 


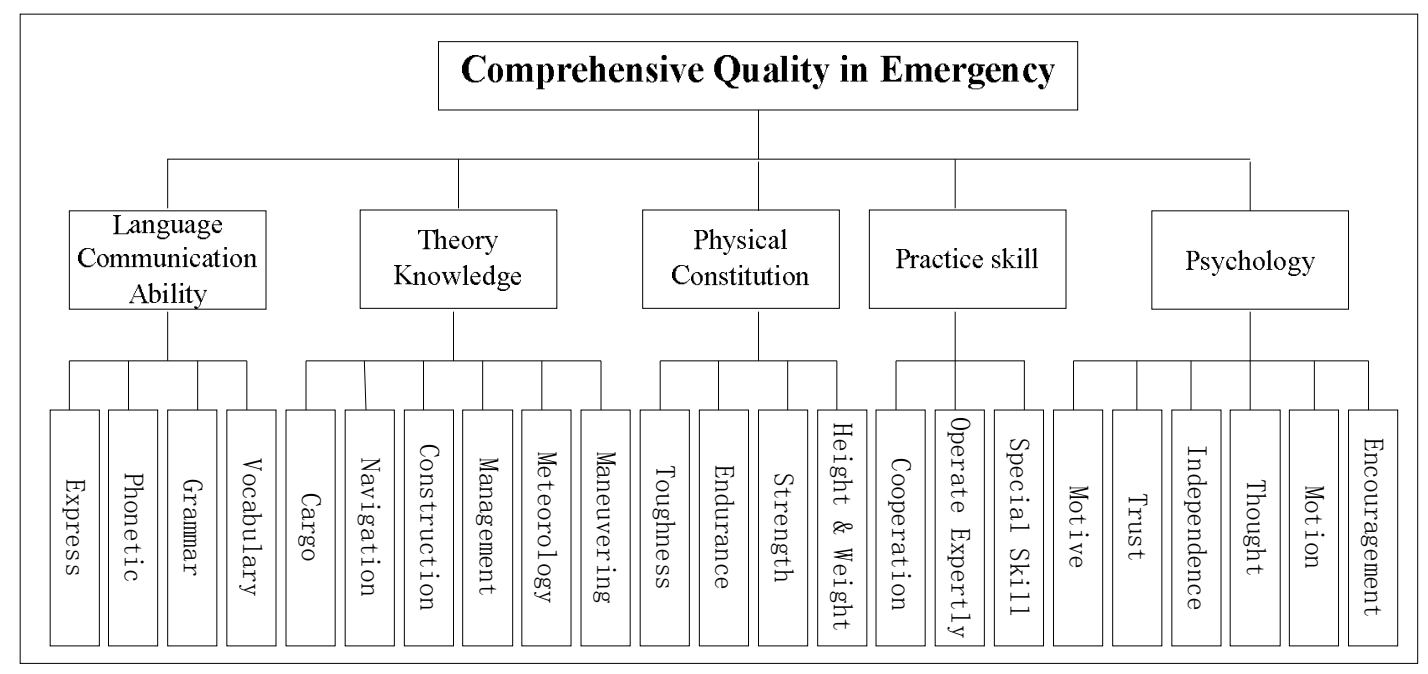

Fig. 1 Evaluation Index System

\section{AHP Analytic Hierarchy Process Theory}

To construct the hierarchical structure of the crew quality evaluation index system in an emergency situation, we weigh the comprehensive index value according to the following formula:

$$
S=\sum_{i=1}^{n} w_{i} f_{i}\left(I_{i}\right)
$$

We weigh rating index based on Analytic Hierarchy Process; The relative weights of elements for the criterion are calculated by the judgment matrix.

$$
\mathrm{HW}=\lambda \mathrm{W}
$$

Check the reliability of evaluation matrix.

$$
C I=\frac{\lambda_{\max }-n}{n-1}
$$

We can get the comprehensive measurement value of the quality evaluation index system of the crew in the emergency condition.

$$
S=\sum w_{i} f_{i}\left(I_{i}\right) \quad i=1,2, \mathrm{~L} n
$$

We combine these separate weights for each specific indicator relative to the highest level of the combination of weight values.

$$
w_{i}=\prod_{j=1}^{k} w_{j}
$$

The formula of the biggest eigenvalue of judgment matrices :

$$
\lambda_{\max }=\sum_{i=1}^{n} \frac{(A W) i}{n W i}
$$

Check the Consistency 


$$
\begin{aligned}
& C I=\frac{\lambda_{\max }-n}{n-1} \\
& C R=\frac{C I}{R I}<0.10
\end{aligned}
$$

\section{Setup Judgment Matrices}

The hierarchical structure of this paper is based on the evaluation index system of the crew's quality under the emergency conditions established above, and test the consistency, and weigh the value of each index layer as follow:

$$
\left[\begin{array}{ccccc}
1 & 2 & 3 & 3 & 2 \\
1 / 2 & 1 & 3 & 3 & 2 \\
1 / 3 & 1 / 3 & 1 & 1 & 1 / 3 \\
1 / 3 & 1 / 3 & 1 & 1 & 1 / 2 \\
1 / 2 & 1 / 2 & 2 & 2 & 2
\end{array}\right]
$$

$\lambda 1=5.21, \mathrm{~W}=(0.336421169,0.3556669,0.0918504,0.091265,0.197895) \mathrm{CR}=0.02852<0.1$

$$
\left[\begin{array}{cccccc}
1 & 7 & 5 & 3 & 3 & 2 \\
1 / 7 & 1 & 1 / 5 & 1 / 3 & 1 / 3 & 1 / 3 \\
1 / 5 & 5 & 1 & 1 & 1 & 1 / 3 \\
1 / 3 & 3 & 1 & 1 & 1 & 1 \\
1 / 3 & 3 & 1 & 1 & 1 & 1 / 3 \\
1 / 2 & 3 & 3 & 1 & 3 & 1
\end{array}\right]
$$

$\lambda 2=6.23545, \mathrm{~W}=(0.3825,0.0456,0.1124,0.1324,0.1136,0.2125) \mathrm{CR}=0.042587<0.1$.

$$
\lambda 3=3.02532, \mathrm{~W}=(0.702546,0.1825634,0.112546) \mathrm{CR}=0.0425364<0.1 .
$$

$\lambda 4=4.12356, \mathrm{~W}=(0.05925,0.39925,0.43456,0.1112321), \mathrm{CR}=0.04251<0.1$.

$\lambda 5=6.5025, \mathrm{~W}=(0.32563,0.22538,0.12540 .0 .055410 .1625410 .0523) \quad \mathrm{CR}=0.081147<0.1$.

We can get the consistency of judgment matrices from the above analysis according to the requirement.

\section{Main Factor s Analysis}

The characteristics of international, liquidity and risk of Professional seafarers has asked the seaman to have firm political direction, a strong sense of patriotism, highly organized and disciplined, good quality, skilled professional knowledge, solid practical skills, certain management ability, good safety and environmental protection consciousness in the maritime education 
Good psychological quality: Once the pirates attack and the shipwreck happens, captain and crew should have good psychological quality, for the matters in different situations, to develop contingency plans. At the same time, the emergency response mechanism should be started in time to relieve the psychological trauma of the crew members.

Good physical fitness: physical and mental health, strong will, full vitality are the symbol of social civilization and progress. In the harsh environment of the sea, we need to overcome natural disasters, to fight for the victory of the pirates in lasting combat.

Mastering the theoretical knowledge: In the course of anti-piracy, we should use a lot of professional knowledge, we must firstly be familiar with the geography, hydrology at this sea, understanding meteorological conditions in response to attacks; in fighting piracy the ship handling, driving technology, more knowledge of ship structures. In addition, we will more use basic safety of navigation, advanced fire fighting, proficient in first aid, radar avoidance and the theoretical and practical knowledge of GMDSS. It is necessary for candidates in the learning process to master STCW78/95 theoretical knowledge under the Convention.

Communication skills: international crew should have a certain standard of English, especially higher listening and speaking abilities. So in the process of cooperation with foreign crew, they can break down language barriers to enhance effectiveness of beating the pirates.

\section{Practice and Verification}

On May, 20th, 2009, Chinese commercial vessel "New Glory" was attacked by pirates at the sea area 110miles far from Yading Gulf Mokaro. After 25-minutes flight, they succeeded in getting rid of attacking. On November,12, 2010, Chinese Ocean-going Shipping Limited Company vessel "Prosperous" defeated the pirates who wanted to attack them; Traffic Transportation Ministry Chinese Ocean-going Shipping Group praised them highly for being faithful in the discharge of one's duties and not fearing violence.

The main Experiences that ocean-going vessel can defeat the pirates are as following:

In emergency, the captain led the whole staff to fight with the pirates without hesitation and could win the fighting, because they have a good psychology condition. On the other hand, the ability to deal with a contingency or emergency and on-scene experiences in fighting the pirates is main reason. Of course, they can not succeed without professional knowledge and fair language communication ability.

\section{References}

[1] QFD Institute. http://www.qfdi.org/workshop_ahp.htm. Retrieved 2007-08-21.

[2] http://thequalityportal.com/q_ahp.htm. Retrieved 2007-08-21.

[3] Dyer, J. S. (1990): Remarks on the Analytic Hierarchy Process. In: Management Science, 36 (3), S. 249-258.

[4] Dyer, J.S. (1990b), "A clarification of 'Remarks on the analytic hierarchy process', Management Science, Vol. 36 No.3, pp.274-5.

[5] Holder, R.D., Some Comment on the Analytic Hierarchy Process, Journal of the Operational Research Society, 1990, 41, 11 